\title{
Diagnostic and therapeutic considerations for obscure gastrointestinal bleeding in patients with chronic kidney disease
}

\author{
Mayssan Muftah ${ }^{a}$, Ramzi Mulki ${ }^{b}$, Tanvi Dhere ${ }^{b}$, Steven Keilin ${ }^{b}$, Saurabh Chawlab,c \\ Emory University School of Medicine; Grady Memorial Hospital, Atlanta, USA
}

\section{Abstract}

\begin{abstract}
Recurrent obscure gastrointestinal bleeding amongst patients with chronic kidney disease is a challenging problem gastroenterologists are facing and is associated with an extensive diagnostic workup, limited therapeutic options, and high healthcare costs. Small-bowel angiodysplasia is the most common etiology of obscure and recurrent gastrointestinal bleeding in the general population. Chronic kidney disease is associated with a higher risk of gastrointestinal bleeding and of developing angiodysplasia compared with the general population. As a result, recurrent bleeding in this subgroup of patients is more prevalent and is associated with an increased number of endoscopic and radiographic procedures with uncertain benefit. Alternative medical therapies can reduce re-bleeding; however, more studies are needed to confirm their efficacy in this subgroup of patients.
\end{abstract}

Keywords Obscure gastrointestinal bleeding, Chronic kidney disease, Angiodysplasia, arteriovenous malformations, Small-bowel bleeding

Ann Gastroenterol 2019; 32 (2): 1-11

\section{Introduction}

Chronic kidney disease (CKD) is an independent risk factor for gastrointestinal (GI) bleeding as it is associated with an increased risk of gastritis, peptic ulcer disease and angiodysplasia [1-5]. Patients with GI bleeding and comorbid CKD have worse outcomes than patients who have normal renal function $[2,6]$ and exhibit higher mortality than the general population (odds ratio [OR] 1.8, 95\% confidence interval [CI] 1.7-1.9; $\mathrm{P}<0.001$ for $\mathrm{CKD}$ ). The risk of mortality increases with disease progression to end-stage renal disease (ESRD) (OR 2.5, 95\%CI 1.4-4.6; $\mathrm{P}=0.002$ ) [6].

Approximately $5-10 \%$ of patients overall present with obscure GI bleeding (OGIB) [7-9], defined as recurrent or persistent GI bleeding without an obvious etiology on esophagogastroduodenoscopy (EGD), colonoscopy, or

${ }^{\mathrm{a}}$ Department of ${ }^{\mathrm{a}}$ Medicine (Mayssan Muftah); ${ }^{\mathrm{b}}$ Medicine, Division of Digestive Diseases, Emory University School of Medicine (Ramzi Mulki, Tanvi Dhere, Steven Keilin, Saurabh Chawla); 'Grady Memorial Hospital (Saurabh Chawla), Atlanta, United States

\section{Conflict of Interest: None}

Correspondence to: Saurabh Chawla, MD, Associate Professor of Medicine, Division of Digestive Diseases, Emory University School of Medicine, 49 Jesse Hill Jr Drive, Suite 431, Atlanta GA 30322, USA, e-mail: saurabh.chawla@emory.edu

Received 17 October 2018; accepted 18 November 2018; published online 20 December 2018

DOI: https://doi.org/10.20524/aog.2018.0341 radiographic imaging [7]. The recent American College of Gastroenterology guidelines recommended reclassification of OGIB as small-bowel bleeding, as about $75 \%$ of OGIB originates in the small bowel $[7,10,11]$.

OGIB is a common dilemma for the gastroenterologist as it is commonly associated with an extensive diagnostic workup with limited yield. Management of this condition is more challenging in patients with CKD. Additionally, healthcare costs are higher in CKD patients with anemia compared to those without, in part because of a higher frequency of GI workup for bleeding [12], higher rates of re-bleeding (OR 2.5, 95\%CI 1.5-4.1; $\mathrm{P}<0.001$ ), higher rates of OGIB, increased transfusion requirements, and longer hospital stays [6]. Given these challenges, the aim of this article was to review the evaluation and management of smallbowel and OGIB bleeding in patients with CKD. Table 1 lists all identifiable studies on GI bleeding in this cohort of patients.

\section{Anemia and GI bleeding in CKD}

The prevalence of anemia in patients with CKD is twice that of the general population ( $15.4 \%$ vs. $7.6 \%)$, and increases with disease progression (8.4\% in Stage 1 CKD vs. $53.4 \%$ in Stage 5 CKD) [13]. This is due to a combination of anemia of chronic disease, erythropoietin deficiency and iron deficiency [14].

A major component of iron deficiency anemia in these patients includes blood losses associated with routine hemodialysis (HD), particularly because of associated heparin infusions [14]. However, they also have a higher prevalence of GI blood losses compared with the general population, largely 
attributed to uremic platelet dysfunction $[15,16]$. Uremia causes impaired function of platelet glycoproteins GPIIb/IIIa, altered release of adenosine diphosphate and serotonin, and impaired prostaglandin and arachidonic acid metabolism, which together compromise platelet adhesion and aggregation [17]. Given the increased platelet dysfunction that occurs with progressive CKD, GI bleeding is an expected complication seen in these patients [18]. In one study, chromium-labeled red blood cells were used to evaluate the amount of GI blood loss in patients with CKD compared to patients with normal renal function. HD patients were found to have more occult GI blood losses (6.27 mL/day) compared with control patients $(0.83 \mathrm{~mL} /$ day $)$ and CKD patients not yet on $\mathrm{HD}$ (3.15 mL/day) [19].

Patients with CKD have been reported to have higher rates of GI bleeding secondary to peptic ulcer disease and angiodysplasia compared with the general population. In a study evaluating anemic patients with non-dialysis dependent CKD stages 3-5, 52.9\% were found to have sources of GI bleeding on upper and lower endoscopy. Gastric lesions were found more frequently in patients with stage $5 \mathrm{CKD}$ compared to those with stages 3-4 CKD [20].

Peptic ulcer disease is a common cause of upper gastrointestinal bleeding (UGIB) in patients with CKD. In a cohort study, investigators followed 796 patients who had just initiated HD for a 6-year period, along with 3184 age- and sexmatched patients without CKD, and compared rates of UGIB. The rate of UGIB was higher for the HD patients (hazard ratio [HR] 1.27, 95\%CI 1.03-1.57). The most common etiology of this bleeding was peptic ulcer disease [21]. Laeeq et al described the causes and characteristics of UGIB in ESRD patients and found that the most common findings were erosions (55.9\%) and ulcers (30.3\%). More than half (55.9\%) of patients required therapeutic intervention [22].

Although there is an increased incidence of peptic ulcer disease in CKD, this is often an easily identifiable and treatable cause of GI bleeding. However, angiodysplasia is typically the cause of small-bowel and recurrent bleeding and is more challenging to identify and manage. Even prior to the advances in small-bowel evaluation, patients with CKD were described as having a higher incidence of angiodysplasia of the stomach or proximal small bowel. One study evaluated the etiologies of UGIB in patients with CKD compared with the general population and found that the former had angiodysplasia as the most common source of bleeding (rate of $50 \%$ vs. 11\%) [3]. Another study evaluated 727 patients who underwent endoscopy for UGIB, 60 of whom had CKD. In this cohort, they found that the prevalence of angiodysplasia was higher in those with renal dysfunction overall and increased with the duration of comorbid CKD and need for hemodialysis [23].

With the advent of video capsule endoscopy (VCE), one prospective study showed that patients with $\mathrm{CKD}$ were at higher risk (OR 4.5, 95\%CI 1.9-10.6; $\mathrm{P}=0.0007$ ) of having small-bowel angiodysplasia compared with the general population [24]. CKD was also found to be an independent risk factor for small-bowel bleeding from vascular lesions [5]. Lastly, another study evaluating patients who underwent capsule endoscopy noted a higher prevalence of vascular lesions in patients on HD (61.5\% vs. $15.8 \%)$ [25]. These studies suggest that not only do patients with CKD have a higher prevalence of angiodysplasia compared with the general population, but bleeding from angiodysplasia in this population is also the leading cause of recurrent bleeding [3].

\section{Endoscopic evaluation of OGIB}

The literature on the utility of endoscopic evaluation in those with recurrent OGIB in ESRD patients is sparse. Typically, patients with recurrent GI bleeding of unidentifiable cause on upper and lower endoscopy are first evaluated with repeat upper or lower endoscopy based on the characteristics of the bleeding. If unrevealing, this should then be followed by small-bowel evaluation [8].

\section{Push enteroscopy (PE)}

In those presenting with recurrent melena or hematemesis, PE may be a better alternative than EGD for a second look, as it has a higher diagnostic yield with the addition of a limited smallbowel evaluation $[8,26]$. It is particularly useful if proximal small-bowel lesions are suspected, as it has a higher yield in the proximal small bowel than VCE and allows for therapeutic intervention [8]. A review of patients who underwent capsule endoscopy found that, of those with small-bowel angiodysplasia, $78.3 \%$ had lesions within the first $25 \%$ of small-bowel transit and $66.8 \%$ had lesions in the duodenum or at the ligament of Treitz, easily reached via PE [27]. Another study investigated the distribution of angiodysplastic lesions in patients who presented with OGIB. Eighty percent of patients had angioectasias in the jejunum, $51 \%$ in the duodenum, and $22.8 \%$ in the stomach [28]. However, of those with small-bowel bleeding secondary to non-vascular lesions, the yield of PE is suboptimal and capsule endoscopy was found to be superior $[8,29,30]$.

Given the yield of PE for vascular lesions, it may be a reasonable next step for evaluation of OGIB in CKD patients when there is high suspicion of an upper GI source. However, there are no studies examining the use of PE in OGIB in these patients.

\section{VCE}

If evaluation with $\mathrm{PE}$ is negative, the next step in evaluating OGIB is with VCE. However, if there is not high suspicion of a proximal small-bowel lesion, VCE would be a more appropriate first step in evaluating OGIB because it has a superior overall yield to $\mathrm{PE}$, due to its ability to visualize the entire small bowel [8,29-31]. The overall diagnostic yield has been reported to range from $38-83 \%$ [8]. A 2005 meta-analysis of 14 studies found that the diagnostic yield of capsule endoscopy was superior to that of PE ( $63 \%$ vs. $28 \%$ ) for OGIB, and to that of small-bowel barium radiography (67\% vs. $8 \%$ ) for any finding when evaluating patients with OGIB. The number needed to test to find an additional clinically significant finding with 
Table 1 Studies on gastrointestinal bleeding in patients with chronic kidney disease

\begin{tabular}{ll} 
Study & Brief study summary \\
\hline Rosenblatt et al., 1982 & $\begin{array}{l}\text { Evaluated GI blood losses with chromium labeled red cells. HD patients were found to have blood losses } \\
\text { of } 6.27 \mathrm{ml} / \text { day, CKD patients not yet on HD were found to have blood losses of 3.15 ml/day, and control } \\
\text { patients with losses of } 0.83 \mathrm{ml} / \text { day. Complete gastrointestinal evaluation of the HD patients showed mucosal } \\
\text { abnormalities throughout [19] }\end{array}$ \\
& $\begin{array}{l}\text { Evaluated the diagnostic utility of different laboratory values for detecting bleeding related gastrointestinal } \\
\text { lesions that were then identified on EGD and colonoscopy in non-dialysis dependent stage 3-5 CKD. } \\
\text { Transferrin saturation<20\% was found to have sensitivity of 59\% and specificity of } 74 \% \text { for identifiable } \\
\text { gastrointestinal lesions. Stage } 5 \text { CKD was found to be an independent risk factor for GI lesions [20] }\end{array}$ \\
\hline Yang et al., 2012 Found that the incidence of UGIB was roughly double that of the general population and has remained steady \\
in contrast to declining rates in the general population[2]
\end{tabular}

Peptic ulcer disease

\begin{tabular}{ll}
\hline Chalasani et al., 1996 & $\begin{array}{l}\text { In CKD patients undergoing EGD for UGIB, gastric ulcer (37\%) and duodenal ulcer (23\%) were the most } \\
\text { frequently identified causes [23] }\end{array}$ \\
Laeeq et al., 2017 & $\begin{array}{l}\text { Described causes and characteristics of UGIB in ESRD patients. The most common endoscopic findings were } \\
\text { erosions (55.9\%) and ulcers (30.3\%). Factors associated with need of endoscopic therapeutic intervention were: } \\
\text { combined presentation of hematemesis and melena }(\mathrm{P}=0.033) \text {, ulcer }(\mathrm{P}=0.002) \text {, and associated chronic liver } \\
\text { disease }(\mathrm{P}=0.015) \text { [22] }\end{array}$ \\
\hline
\end{tabular}

Angiodysplasia

\begin{tabular}{|c|c|}
\hline Zuckerman et al., 1985 & $\begin{array}{l}\text { Of patients evaluated for UGIB, angiodysplasia and erosive esophagitis were significantly more common causes } \\
\text { of bleeding in patients with CKD than those without. Angiodysplasia of the stomach or duodenum was the } \\
\text { most common source of bleeding and the most frequent source of re-bleeding }(53 \%) \text { in CKD patients [3] }\end{array}$ \\
\hline Chalasani et al., 1996 & $\begin{array}{l}\text { Found that of those undergoing EGD for UGIB, the prevalence of vascular ectasia was higher in those with } \\
\text { renal dysfunction overall (13\% vs } 1.3 \% \text { in those without CKD) and increased with the duration of comorbid } \\
\text { CKD and need for hemodialysis [23] }\end{array}$ \\
\hline Ohmori et al., 2012 & $\begin{array}{l}\text { Evaluated patients that underwent VCE for OGIB. Vascular lesions were significantly more common in those } \\
\text { on HD compared to control }(\mathrm{P}<0.001)[25]\end{array}$ \\
\hline Holleran et al., 2013 & $\begin{array}{l}\text { Evaluated patients with small bowel angiodysplasia and associated risk factors and comorbidities. Patients with } \\
\text { CKD had an OR of } 8.4 \text { of having small bowel angiodysplasia[24] }\end{array}$ \\
\hline Sakai et al., 2013 & $\begin{array}{l}\text { CKD stage } 4 \text { or higher was found to be an independent predictor of the presence of vascular lesions on VCE in } \\
\text { patients with overt OGIB with an OR } 4.03(95 \%=\text { CI } 1.45-11.1)[5]\end{array}$ \\
\hline
\end{tabular}

Diagnostic evaluation

\begin{tabular}{ll}
\hline Oliveras et al., 1998 & $\begin{array}{l}\text { Evaluated the utility of scintigraphy in localizing bleeding from angiodysplasia in two cohorts - those with } \\
\text { CKD and those without. In the CKD cohort, the sensitivity was } 88.9 \%, \text { compared to the 30\% sensitivity of } \\
\text { colonoscopy [62] }\end{array}$ \\
\hline $\begin{array}{l}\text { Docherty et al., 2015 } \\
\text { Assessed the diagnostic yield of VCE in evaluating OGIB in patients with CKD. 51\% had findings on VCE, and } \\
\text { Magalhaes-Costa et al., 2015 had angiodysplasia as the cause of bleeding [35] }\end{array}$ & $\begin{array}{l}\text { Evaluated the rate of recurrent OGIB after a negative VCE and found that patients with CKD had an increased } \\
\text { HR of 3.498 for re-bleeding on univariate analysis (95\% CI=1.265-9.671, P=0.016) [52] }\end{array}$ \\
\hline
\end{tabular}

capsule endoscopy over the other two modalities was 3 [30].

VCE is most effective when done soon after the onset of bleeding. One study showed that capsule endoscopy had a markedly higher yield if it was performed within the first
15 days after the onset of overt GI bleeding rather than later (91\% positive findings vs. 34\%) [32]. Another study by Pennazio et al found that the diagnostic yield of VCE was much higher in patients with ongoing overt bleeding than in those 


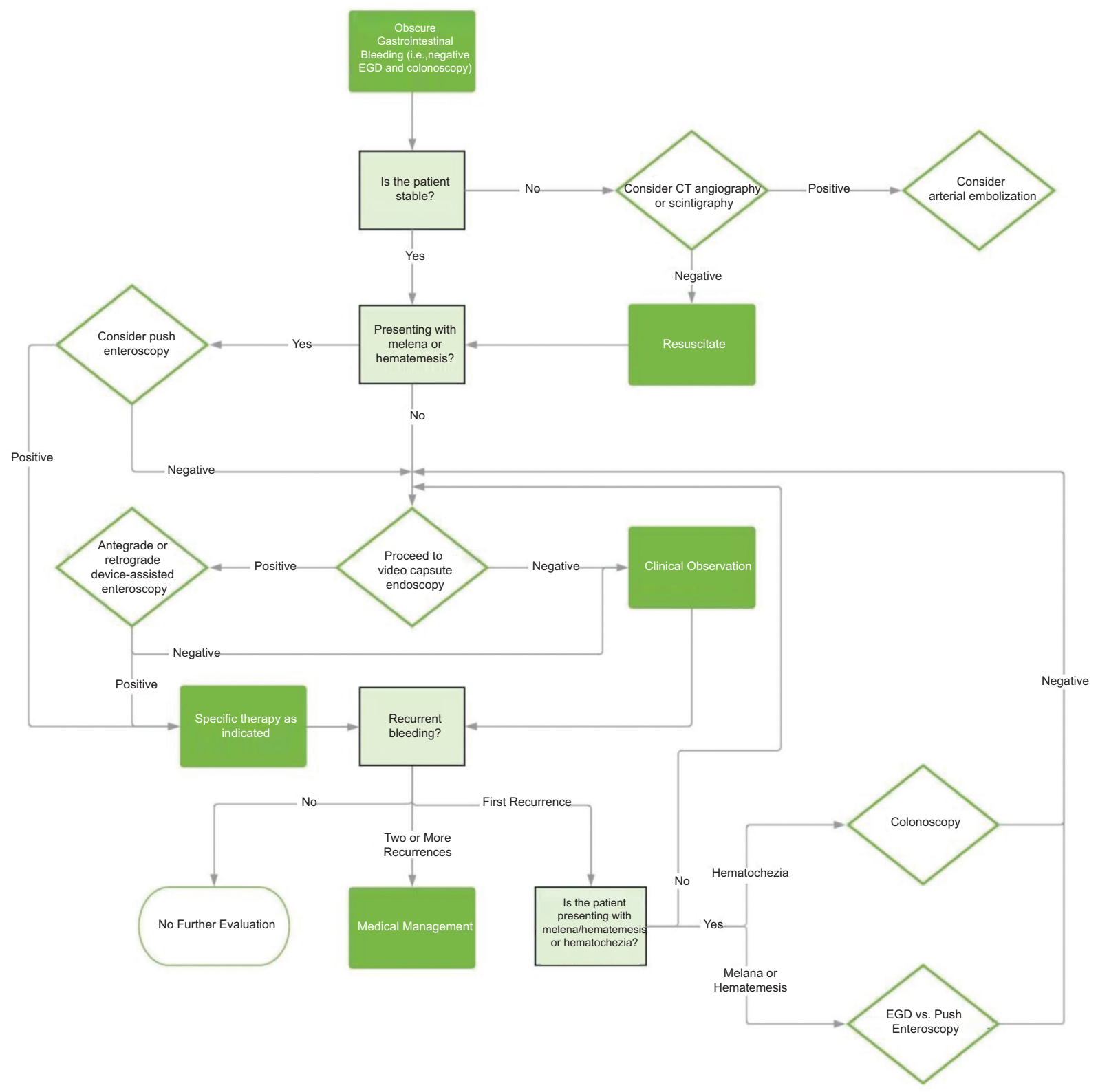

Figure 1 Above is a recommended diagnostic algorithm for obscure gastrointestinal bleeding in patients with chronic kidney disease. Adapted from "ACG Clinical Guideline: Diagnosis and Management of Small Bowel Bleeding" [8] and "Small-bowel capsule endoscopy and device-assisted enteroscopy for diagnosis and treatment of small-bowel disorders: European Society of Gastrointestinal Endoscopy (ESGE) Clinical Guideline” [31] EGD, esophagogastroduodenoscopy; CT, computed tomography

without active bleeding (92.3\% vs. $12.9 \%)$. In those with prior episodes, the earlier the VCE was done after the cessation of bleeding, the higher the yield [33]. Other factors associated with increased positive capsule endoscopy results included overt bleeding, use of non-steroidal anti-inflammatory drugs and a larger transfusion requirement [34].

There is one study on the yield of capsule endoscopy in the evaluation of OGIB in patients with CKD. About half of the patients had positive VCE and $33.3 \%$ had angiodysplasia as the cause of bleeding. The overall yield was lower than in the general population, but the study itself was limited by the number of patients included [35].

\section{Device-assisted enteroscopy (DAE)}

DAE includes double-balloon (DBE), single-balloon (SBE) and through-the-scope balloon-assisted enteroscopy, and spiral enteroscopy (SE) [36]. These techniques are used for extensive evaluation of the small bowel (with complete 
visualization in about $5-40 \%$ of patients) and allow for therapeutic intervention $[8,37]$.

Reported diagnostic yields for DAE are $60-80 \%$ for DBE [8,38-40], 33-74\% for SBE [8,41-43], and 33-75\% for SE [44-46]. The 2017 guidelines from the American Society of Gastrointestinal Endoscopy on the endoscopic evaluation of small-bowel bleeding suggest that all the DAE modalities have similar diagnostic and therapeutic outcomes [9]. Timing of evaluation improves the yield of these modalities. A 2010 retrospective study found that the overall yield of DBE was higher if the examination was performed within a month of the most recent episode of bleeding ( $84 \%$ vs. $57 \%$ ) [47]. VCE and device-assisted enteroscopy have similar diagnostic yields and are typically considered complementary modalities $[8,48,49]$. There are no studies on the use of DAE in evaluating OGIB in those with comorbid CKD.

\section{Recurrent bleeding following negative endoscopic evaluation}

It is not uncommon for patients with OGIB and negative small-bowel evaluation to present with recurrent bleeding, particularly patients with CKD. One study by Curdia Goncalves et al followed 68 patients with OGIB and negative VCE for 32 months. Re-bleeding occurred in $23.5 \%$ of patients at an average of 15 months following the initial presentation [50]. Shinozaki et al followed 42 patients with overt OGIB and negative $\mathrm{DBE}$ to evaluate rates of re-bleeding. Re-bleeding occurred in $38 \%$ of patients at a mean follow up of 54 years [51].

Another retrospective study evaluated the rate of recurrent OGIB after a negative VCE. Re-bleeding occurred in $27.4 \%$ of patients at an average of 15 months from the initial presentation; $22.6 \%$ of the patients who suffered re-bleeding had confirmed angiodysplasia. Factors associated with re-bleeding included age $>65$ years, CKD, aortic stenosis, anticoagulant use and overt bleeding. Patients with CKD had an increased risk of rebleeding on univariate analysis (HR 3.498, 95\%CI 1.265-9.671; $\mathrm{P}=0.016)[52]$.

\section{Yield of repeat endoscopy}

In the setting of recurrent bleeding, the data on repeat small-bowel evaluation are limited and conflicting. In the study by Curdia Goncalves et al, $57.4 \%$ of patients who re-bled underwent further diagnostic testing and a cause of bleeding was only found $13 \%$ of the time [50]. Conversely, another study demonstrated a high yield of repeat VCE. Of those with negative prior VCE, $75 \%$ had findings on repeat VCE and $62.5 \%$ of these patients had a change in management [53].

In a study by Shinozaki et al that included patients with initial negative DBE, of those patients who re-bled, $88 \%$ underwent further diagnostic evaluation with a yield of $71 \%$, and of those with a confirmed source, $70 \%$ were in the small bowel [51]. In another study that looked at the yield of repeat DBE for recurrent OGIB, $53.1 \%$ of patients had positive findings and of these $94.1 \%$ were angiodysplasia. All identified bleeding lesions were managed with argon plasma coagulation. However, the yield of repeat DBE for recurrent bleeding was only high in those with previously positive DBE. Those with initially negative DBE had negative evaluations the second time [54]. There are no studies on the yield of repeat endoscopy for recurrent OGIB in patients with CKD.

\section{Radiologic evaluation}

Radiographic modalities also play a role in the work up of OGIB, but in general have more utility in the setting of overt bleeding. In those with ongoing bleeding and hemodynamic stability, computed tomography angiography (CTA) and scintigraphy may be useful in identifying the site of bleeding and allowing for targeted intervention. Patients with brisk bleeding are best evaluated with CTA. A meta-analysis of the use of CTA in those presenting with acute GI bleeding showed an overall sensitivity of $89 \%$ and a specificity of $85 \%$ [55]. Patients with positive CTA are also more likely to have positive findings on enteroscopy [56]. Given the risk of contrast nephropathy, CTA has traditionally had a limited role in evaluation of OGIB in CKD and has not been well studied.

Patients with slower rates of bleeding can be better evaluated with scintigraphy, particularly if a patient presents later after the onset of bleeding [8]. The overall diagnostic yield varies among reports in the literature (45-73\%) [57-61]. One prospective study assessed the use of scintigraphy in the evaluation of obscure overt bleeding and found an overall yield of $65 \%$ with a localization accuracy of $75 \%$ [61]. Another study evaluated the utility of scintigraphy in localizing bleeding from angiodysplasia in patients with comorbid CKD compared with colonoscopy and found that scintigraphy had a much higher sensitivity ( $88.9 \%$ vs. $30 \%$ ) [62]. Scintigraphy is limited by its ability to characterize the source of bleeding and variable accuracy due to the potential for false localization of bleeding with rapid transit of labeled red blood cells through the smallbowel lumen $[8,57,60,61,63,64]$.

Diagnostic angiography is typically reserved for the hemodynamically unstable, particularly those with large transfusion requirements and who present early after the onset of bleeding, as the yield is highest in this setting [8,65-68]. The benefit of this approach is its therapeutic potential. It is otherwise not used often for diagnosis because of its invasive nature and associated risks [8]. The overall yield of conventional angiography ranges between $20-51 \%$ [66,69-71]. Despite the utility of angiography in diagnosing the cause of OGIB, VCE remains superior and has a higher diagnostic yield [69]. As it poses similar risks to those associated with CTA, contrast exposure limits the role of angiography in evaluating OGIB in patients with CKD.

In addition to concerns regarding contrast exposure, patients who present with recurrent bleeding are more likely to get multiple radiographic scans with increased radiation exposure. One study evaluated the cancer risk associated with each CTA and found that abdominal CTAs specifically confer 
the highest cancer risk, estimated to be around 36 cancer risks per 1 million procedures [72].

CT or magnetic resonance enterography (CTE or MRE) can be used as part of the workup of OGIB. However, in regard to bleeding specifically from vascular lesions and angiodysplasia, VCE has superior yield and higher sensitivity in identifying these lesions [73-77]. Thus, CTE or MRE have little utility as part of the initial work up of OGIB in patients with CKD.

\section{Endoscopic intervention}

Specific interventions once a culprit lesion is found depends on the type of lesion itself. While it can be treated with electrocautery, angiodysplasia is primarily treated with argon plasma coagulation (APC) via PE or DAE. Other methods of hemostasis include injection therapy or mechanical hemostasis with clips. As mentioned above, DAE is reserved largely for these therapeutic interventions [9].

The data regarding long-term outcomes are controversial. However, the majority of studies report no difference in longterm outcomes in those treated with endoscopy vs. observation alone $[78,79]$. One systematic review looked at the long-term outcomes of patients with bleeding from angiodysplasia managed with endoscopic therapy versus observation. Rebleeding rates in the two groups were $42.7 \%$ and $49.2 \%$ [78]. Another systematic review found that the pooled re-bleeding rate of small-bowel angiodysplasia following endoscopic intervention was 45\% [80]. A 2013 study reviewed patients who underwent DAE for small-bowel bleeding from angiodysplasia. The overall diagnostic yield was $74 \%$ and the therapeutic yield $67 \%$; however, there was no difference in long-term outcomes between those patients who received endoscopic therapy and those who underwent observation alone: re-bleeding occurred in $30 \%$ of the former and $20 \%$ of the latter [81]. A 2012 retrospective study evaluated re-bleeding rates in patients with OGIB who received endoscopic therapy (primarily APC) for small-bowel vascular lesions. The re-bleeding rate was $46 \%$ at 36-month follow up [82]. A 2009 survey study evaluated the long-term outcomes of 101 patients following DBE for OGIB. Of those followed, 40 had angiodysplasia treated with APC; of these 40 patients, $54 \%$ had re-bleeding or recurrent need for iron replacement and blood transfusions [83]. A 1996 study evaluated patients with OGIB who underwent PE. Less than half of patients treated with electrocautery for angiodysplasia had a good outcome, defined as not having recurrent anemia or blood transfusion requirements [84]. Lastly, a 1987 study compared the long-term outcomes of those with angiodysplasia treated either with surgical resection, endoscopic electrocautery or transfusion alone. No modality was statistically superior in treating and preventing recurrent bleeding [85].

Conversely, a few studies showed effective reduction of bleeding with endoscopic therapy. A 1996 study retrospectively evaluated the long-term follow up of 83 patients found to have small-bowel angiodysplasia on PE. Of these patients, 55 underwent electrocautery and 28 did not, with a mean follow up of 30 months for the former and 26 months for the later. The patients treated with electrocautery had a statistically significant reduction in recurrent bleeding and blood transfusions [86]. Similarly, a prospective 2006 study evaluated long-term follow up in 100 patients who underwent argon plasma ablation therapy for colonic angiodysplasia: $85 \%$ had stabilized hemoglobin concentration without recurrence of overt bleeding after a 20-month follow up [87]. Lastly, a 2012 prospective study evaluated the long-term outcomes of 61 patients following SE, of whom 45 underwent endoscopic therapy. There was a statistically significant reduction in the rate of overt bleeding, transfusion requirements, mean hemoglobin and need for iron supplementation over an average of 25.3-month follow up [88]. There are no studies on endoscopic intervention for OGIB in patients with CKD.

\section{Non-endoscopic management of GI bleeding}

Considering the low efficacy of endoscopic management in the long-term prevention of recurrent bleeding from angiodysplasia, it is important to consider non-endoscopic therapies.

\section{Transfusions and iron replacement therapy}

As discussed above, observation alone with as-needed transfusions and iron replacement for anemia are non-inferior to endoscopic management. This is potentially a viable option for those for whom sedation presents a high risk, or have had multiple prior endoscopic interventions with recurrent or persistent bleeding. It is important to note, however, that oral iron is virtually ineffective at replenishing iron stores in those with deficiency and comorbid CKD. It is thought that uremia prevents the GI absorption of iron [14].

A prospective study compared placebo with oral and intravenous (IV) iron replacement in patients with iron deficiency anemia on HD. Both oral iron and placebo were ineffective in improving the patients' hemoglobin levels, but IV iron was efficacious (with an average rise in hemoglobin from below $7 \mathrm{~g} / \mathrm{dL}$ to above $12 \mathrm{~g} / \mathrm{dL}$ ) [89]. The second study was a randomized control trial of patients iron replete on HD who were initiating erythropoietin for hemoglobin levels less than $8.5 \mathrm{~g} / \mathrm{dL}$. Patients were randomized to placebo, oral iron supplementation or IV iron supplementation. Those on IV iron had larger improvements in their hemoglobin concentrations and were the only group able to maintain ferritin stores. The other two groups had a drop in their ferritin levels over time [90].

\section{Somatostatin analogs}

Increasingly, studies have shown that octreotide is an effective option for the management of bleeding from angiodysplasia and should be strongly considered in those with recurrent bleeding despite endoscopic intervention [91]. 
Octreotide is a somatostatin analog whose reported mechanism of action includes decreasing splanchnic blood flow, inhibiting angiogenesis, improving platelet aggregation and increasing vascular resistance $[79,80,92]$.

A review by Jackson and Gerson found that somatostatin analogs were effective in reducing recurrent bleeding episodes and transfusion requirements with a pooled OR of 14.5 (95\%CI 5.9-36) [80]. A 2010 meta-analysis of studies reporting the use of somatostatin analogs in the treatment of angiodysplasia determined a clinical response of $76 \%$, with a weighted mean difference in transfusion requirements before and after treatment of -2.2 (95\%CI -3.9 to -0.5) [93]. Another study followed patients with recurrent GI bleeding secondary to angiodysplasia after at least 6 months of treatment with a somatostatin analog. Following treatment, the rate of bleeding episodes was reduced from $73 \%$ to $20 \%$, the number of transfusions needed dropped from a median of 10 to 2, and the mean hemoglobin increased from a median of 7 to $10 \mathrm{~g} / \mathrm{dL}$ [94]. Similarly, a prospective study evaluated the efficacy of 1-year octreotide treatment in patients with chronic bleeding secondary to angiodysplasia. Complete response without the need for transfusion or iron supplementation was achieved in $69 \%$ of patients, a partial response in $8 \%$ of patients and no response in $23 \%$ of patients [95].

A 2017 study evaluated the use of combination endoscopic therapy and the somatostatin analog lanreotide compared to endoscopic therapy alone in patients with refractory iron deficiency anemia secondary to small-bowel angioectasia. Combination therapy led to statistically significant reduction in transfusion requirements and bleeding episodes with an increase in hemoglobin compared with the other group [96].

One case series reported 3 patients with CKD and recurrent bleeding secondary to diffuse GI angiodysplasia that responded to 6 months of octreotide therapy [97]. However, no formal studies have examined the efficacy of octreotide in treating angiodysplasia in patients with comorbid CKD.

\section{Thalidomide}

Thalidomide is the most recent addition to the medical armamentarium in treating bleeding from angiodysplasia. Its proposed mechanism of action is related to anti-angiogenic effects at low doses, as the development of angiodysplasia is suspected to be related to elevated levels of vascular endothelial growth factor causing increased angiogenesis [80,92,98,99].

A 2011 randomized control trial revealed that thalidomide was effective in reducing the rates of re-bleeding in patients with recurrent bleeding from angiodysplasia. Patients were randomized to treatment or control (treated with iron therapy) groups and were followed for at least 1 year. Effective response was defined as a 50\% reduction in bleeding episodes. Those treated with thalidomide had a response rate of $71.4 \%$, compared with $3.7 \%$ for the control group. Those treated with thalidomide also had lower transfusion requirements and fewer hospitalizations. Side effects experienced by patients included neuropathy and somnolence [100]. A 2012 prospective study evaluated patients treated with thalidomide for 4 months for refractory bleeding secondary to angiodysplasia. Prior to treatment, the average hemoglobin was $6.5 \mathrm{~g} / \mathrm{dL}$, which increased to $11.3 \mathrm{~g} / \mathrm{dL}$ at 2 months and $12.1 \mathrm{~g} / \mathrm{dL}$ at 4 months of treatment. However, $16.7 \%$ of patients had to stop treatment early because of side effects [101]. One case report described effective treatment of refractory GI bleeding secondary to diffuse angiodysplasia in a patient on HD. The patient had a significant reduction in transfusion requirements and number of angiodysplastic lesions found on endoscopy [102].

\section{Desmopressin}

Given that bleeding in patients with CKD is related to uremic platelet dysfunction, desmopressin can potentially be used as a short-term reversal agent for this acquired coagulopathy in the management of patients presenting with overt or ongoing bleeding $[4,18,103,104]$. However, only limited relevant data are available.

Intranasal or IV desmopressin lasts about $8 \mathrm{~h}$ and can be used for up to two total doses before exhibiting tachyphylaxis [4]. The effect of desmopressin peaks at 1-2 h [103]. A doubleblind crossover study compared the effect of desmopressin to placebo on bleeding times in patients on HD. Those that received desmopressin had a reduction in bleeding time from an average of $21.3 \pm 8 \mathrm{~min}$ to $11.5 \pm 6 \mathrm{~min}$; however, there was no change in hemoglobin or platelet count [105].

The proposed mechanism of action is multifactorial and includes an increased number of von Willebrand Factor (vWF) and Factor VIII (FVIII) complexes, likely via increased release from storage sites, improved platelet membrane receptor binding of the vWF: FVIII complexes [103], and direct action on the platelet membrane leading to increased platelet serotonin uptake and subsequent adenosine triphosphate release $[105,106]$.

It is important to note that the effect of desmopressin on transfusion requirements in those with active bleeding and its clinical utility in preventing GI bleeding have not been studied. Additionally, the same effect of desmopressin in reducing platelet dysfunction is also achieved by HD $[18,107]$. There is reported utility prior to surgical procedures in preventing bleeding, and it may prove to be useful in patients who are about to undergo endoscopic therapy.

\section{Hormonal therapy}

In the 1980s and 90s, hormonal therapy gained traction in the prevention of GI bleeding [108]. However, more recent studies have proven it to be ineffective, particularly in the setting of bleeding from angiodysplasia $[9,80]$. Data on the effect of hormonal therapy in preventing bleeding in those with CKD are controversial and overall lacking [109].

A systematic review by Jackson and Gerson of the management of GI bleeding secondary to angiodysplasia found that hormonal therapy was ineffective overall (OR 1.0, 95\%CI 0.5-1.96) [80]. A multicenter randomized controlled trial enrolled patients with small-bowel angiodysplasia 
into a treatment or control group and found that there was no significant difference between the two groups with regard to the number of bleeding episodes and transfusion requirements [110]. Another cohort study evaluated patients with small-bowel angiodysplasia and found no difference in transfusion requirements between those receiving hormonal therapy versus observation alone [111].

Regarding patients with CKD specifically, there are insufficient data on the use of hormonal therapy to prevent bleeding. The above randomized controlled trial was not sufficiently powered to exclude a benefit in patients with CKD $[109,110]$, in whom it has been shown that hormonal therapy can reduce bleeding times [112-114]. There are case series and case reports suggesting that hormonal therapy has been effective in the management of bleeding from angiodysplasia in patients with CKD [115-118]. Given that the data for the general population show no benefit from using hormonal therapy, until there are studies proving otherwise in the CKD population we would avoid using it in this setting.

\section{Arterial embolization}

With advances in technology allowing for super-selective mesenteric embolization, the overall risks of embolizationparticularly bowel infarction-have decreased with time. However, most data regarding arterial embolization for GI bleeding are from patients with bleeding sources outside of the small bowel [119-122]. Reported clinical success rates range between $63 \%$ and $71.4 \%$, with mortality ranging between $9 \%$ and $19.3 \%[119,121,123]$. There are no studies on the role of arterial embolization in managing OGIB in patients with CKD.

\section{Surgical treatment}

Surgery is typically reserved for refractory and lifethreatening cases of bleeding. The primary surgical intervention is intraoperative enteroscopy with subsequent surgical resection or endoscopic therapy [80]. Surgery is also useful in the lysis of adhesions that would otherwise preclude the employment of advanced endoscopic procedures [9].

Given the high negative predictive value of endoscopic modalities for small-bowel evaluation, there is little to no utility for intraoperative enteroscopy in diagnosis. It is primarily reserved for patients who have a lesion identified by other endoscopic techniques and need further localization during surgery prior to an intervention [124,125].

\section{Concluding remarks}

While peptic ulcer disease is common in CKD, angiodysplasias are the most common culprit ofOGIBin patients with CKD. These patients frequently present with recurrent or OGIB despite endoscopic evaluation and intervention. The available evidence concerning the management of patients with OGIB is ambiguous and systematic reviews suggest no overall difference in outcomes between those who undergo endoscopic versus conservative management for these lesions. Therefore, it is important to weigh the risks and the benefits prior to endoscopic intervention, especially in patients with significant comorbidities. We propose an algorithmic approach to evaluating obscure GI bleeding in patients with CKD based on existing guidelines in Figure 1. There are minimal data on the endoscopic evaluation, intervention and outcomes of OGIB specifically in patients with CKD, and more studies are necessary to assess whether their outcomes compare to those in the general population.

\section{References}

1. Gerson LB. Causes of gastrointestinal hemorrhage in patients with chronic renal failure. Gastroenterology 2013;145:895-897; discussion 897.

2. Yang JY, Lee TC, Montez-Rath ME, et al. Trends in acute nonvariceal upper gastrointestinal bleeding in dialysis patients. J Am Soc Nephrol 2012;23:495-506.

3. Zuckerman GR, Cornette GL, Clouse RE, Harter HR. Upper gastrointestinal bleeding in patients with chronic renal failure. Ann Intern Med 1985;102:588-592.

4. Kalman RS, Pedrosa MC. Evidence-based review of gastrointestinal bleeding in the chronic kidney disease patient. Semin Dial 2015;28:68-74.

5. Sakai E, Endo H, Taniguchi L, et al. Factors predicting the presence of small bowel lesions in patients with obscure gastrointestinal bleeding. Dig Endosc 2013;25:412-420.

6. Hágendorn R, Farkas N, Vincze, et al. Chronic kidney disease severely deteriorates the outcome of gastrointestinal bleeding: A meta-analysis. World J Gastroenterol 2017;23:8415-8425.

7. Raju GS, Gerson L, Das A, Lewis B; American Gastroenterological Association. American Gastroenterological Association (AGA) Institute technical review on obscure gastrointestinal bleeding. Gastroenterology 2007;133:1697-1717.

8. Gerson LB, Fidler JL, Cave DR, Leighton JA. ACG Clinical Guideline: diagnosis and management of small bowel bleeding. Am J Gastroenterol 2015;110:1265-1287.

9. Gurudu SR, Bruining DH, Acosta RD, et al; ASGE Standards of Practice Committee. The role of endoscopy in the management of suspected small-bowel bleeding. Gastrointest Endosc 2017;85:22-31.

10. Pennazio M, Arrigoni A, Risio M, Spandre M, Rossini FP. Clinical evaluation of push-type enteroscopy. Endoscopy 1995;27:164-170.

11. Chong J, Tagle M, Barkin JS, Reiner DK. Small bowel push-type fiberoptic enteroscopy for patients with occult gastrointestinal bleeding or suspected small bowel pathology. Am J Gastroenterol 1994; 89:2143-2146.

12. van Nooten FE, Green J, Brown R, Finkelstein FO, Wish J. Burden of illness for patients with non-dialysis chronic kidney disease and anemiain theUnited States:review of theliterature.JMedEcon2010; 13:241-256.

13. Stauffer ME, Fan T. Prevalence of anemia in chronic kidney disease in the United States. PLoS One 2014;9:e84943.

14. Babitt JL, Lin HY. Mechanisms of anemia in CKD. J Am Soc Nephrol 2012;23:1631-1634.

15. Escolar G, Cases A, Bastida E, et al. Uremic platelets have a 
functional defect affecting the interaction of von Willebrand factor with glycoprotein IIb-IIIa. Blood 1990;76:1336-1340.

16. Boccardo P, Remuzzi G, Galbusera M. Platelet dysfunction in renal failure. Semin Thromb Hemost 2004;30:579-589.

17. Jalal DI, Chonchol M, Targher G. Disorders of hemostasis associated with chronic kidney disease. Semin Thromb Hemost 2010;36:34-40.

18. Kaw D, Malhotra D. Platelet dysfunction and end-stage renal disease. Semin Dial 2006;19:317-322.

19. Rosenblatt SG, Drake S, Fadem S, Welch R, Lifschitz MD. Gastrointestinal blood loss in patients with chronic renal failure. Am J Kidney Dis 1982;1:232-236.

20. Hwang HS, Song YM, Kim EO, et al. Decisive indicator for gastrointestinal workup in anemic patients with nondialysis chronic kidney disease. Int J Med Sci 2012;9:634-641.

21. Kuo CC, Kuo HW, Lee IM, Lee CT, Yang CY. The risk of upper gastrointestinal bleeding in patients treated with hemodialysis: a population-based cohort study. BMC Nephrol 2013;14:15.

22. Laeeq SM, Tasneem AA, Hanif FM, Luck NH, Mandhwani R, Wadhva R. Upper gastrointestinal bleeding in patients with end stage renal disease: causes, characteristics and factors associated with need for endoscopic therapeutic intervention. J Transl Int Med 2017;5:106-111.

23. Chalasani N, Cotsonis G, Wilcox CM. Upper gastrointestinal bleeding in patients with chronic renal failure: role of vascular ectasia. Am J Gastroenterol 1996;91:2329-2332.

24. Holleran G, Hall B, Hussey M, McNamara D. Small bowel angiodysplasia and novel disease associations: a cohort study. Scand J Gastroenterol 2013;48:433-438.

25. Ohmori T, Konishi H, Nakamura S, Shiratori K. Abnormalities of the small intestine detected by capsule endoscopy in hemodialysis patients. Intern Med 2012;51:1455-1460.

26. Hayat M, Axon AT, O'Mahony S. Diagnostic yield and effect on clinical outcomes of push enteroscopy in suspected small-bowel bleeding. Endoscopy 2000;32:369-372.

27. Plotkin E, Imaeda A. Small intestinal angioectasias are not randomly distributed in the small bowel and most may be reached by push enteroscopy. J Clin Gastroenterol 2016;50:561-565.

28. Bollinger E, Raines D, Saitta P. Distribution of bleeding gastrointestinal angioectasias in a Western population. World $J$ Gastroenterol 2012;18:6235-6239.

29. Ge ZZ, Hu YB, Xiao SD. Capsule endoscopy and push enteroscopy in the diagnosis of obscure gastrointestinal bleeding. Chin Med J (Engl) 2004;117:1045-1049.

30. Triester SL, Leighton JA, Leontiadis GI, et al. A meta-analysis of the yield of capsule endoscopy compared to other diagnostic modalities in patients with obscure gastrointestinal bleeding. Am J Gastroenterol 2005;100:2407-2418.

31. PennazioM,SpadaC,EliakimR,etal.Small-bowelcapsuleendoscopy and device-assisted enteroscopy for diagnosis and treatment of small-bowel disorders: European Society of Gastrointestinal Endoscopy (ESGE) Clinical Guideline. Endoscopy 2015; 47:352-376.

32. Bresci G, Parisi G, Bertoni M, Tumino E, Capria A. The role of video capsule endoscopy for evaluating obscure gastrointestinal bleeding: usefulness of early use. J Gastroenterol 2005;40:256-259.

33. Pennazio M, Santucci R, Rondonotti E, et al. Outcome of patients with obscure gastrointestinal bleeding after capsule endoscopy: report of 100 consecutive cases. Gastroenterology 2004;126:643-653.

34. RibeiroI,PinhoR, Rodrigues A,MarquésJ,FernandesC,CarvalhoJ. Obscure gastrointestinal bleeding: Which factors are associated with positivecapsule endoscopyfindings? RevEspEnferm Dig2015; 107:334-339.

35. Docherty E, Koulaouzidis A, Douglas S, Plevris JN. Use of small bowel capsule endoscopy in patients with chronic kidney disease: experience from a University Referral Center. Ann Gastroenterol 2015;28:99-104.

36. Chauhan SS, Manfredi MA, Abu Dayyeh BK, et al; ASGE Technology Committee. Enteroscopy. Gastrointest Endosc 2015; 82:975-990.

37. Moeschler O, Mueller MK. Deep enteroscopy - indications, diagnostic yield and complications. World J Gastroenterol 2015; 21:1385-1393.

38. May A, Nachbar L, Ell C. Double-balloon enteroscopy (pushand-pull enteroscopy) of the small bowel: feasibility and diagnostic and therapeutic yield in patients with suspected small bowel disease. Gastrointest Endosc 2005;62:62-70.

39. Gross SA, Stark ME. Initial experience with double-balloon enteroscopy at a U.S. center. Gastrointest Endosc 2008;67:890-897.

40. Xin L, Liao Z, Jiang YP, Li ZS. Indications, detectability, positive findings, total enteroscopy, and complications of diagnostic double-balloon endoscopy: a systematic review of data over the first decade of use. Gastrointest Endosc 2011;74:563-570.

41. Tsujikawa T, Saitoh Y, Andoh A, et al. Novel single-balloon enteroscopy for diagnosis and treatment of the small intestine: preliminary experiences. Endoscopy 2008;40:11-15.

42. Prachayakul V, Deesomsak M, Aswakul P, Leelakusolvong S. The utility of single-balloon enteroscopy for the diagnosis and management of small bowel disorders according to their clinical manifestations: a retrospective review. BMC Gastroenterol 2013; 13:103.

43. Manno M, Riccioni ME, Cannizzaro R, Andreoli A, Marmo R, Pennazio M. Diagnostic and therapeutic yield of single balloon enteroscopy in patients with suspected small-bowel disease: results of the Italian multicentre study. Dig Liver Dis 2013;45:211-215.

44. Schembre DB, Ross AS. Spiral enteroscopy: a new twist on overtube-assisted endoscopy. Gastrointest Endosc 2009; 69:333-336.

45. Buscaglia JM, Richards R, Wilkinson MN, et al. Diagnostic yield of spiral enteroscopy when performed for the evaluation of abnormal capsule endoscopy findings. J Clin Gastroenterol 2011;45:342-346.

46. Rahmi G, Samaha E, Vahedi K, et al. Multicenter comparison of double-balloon enteroscopy and spiral enteroscopy. J Gastroenterol Hepatol 2013;28:992-998.

47. Shinozaki S, Yamamoto H, Yano T, et al. Long-term outcome of patients with obscure gastrointestinal bleeding investigated by double-balloon endoscopy. Clin Gastroenterol Hepatol 2010; 8:151-158

48. Pasha SF, Leighton JA, Das A, et al. Double-balloon enteroscopy and capsule endoscopy have comparable diagnostic yield in smallbowel disease: a meta-analysis. Clin Gastroenterol Hepatol 2008; 6:671-676.

49. Shishido T, Oka S, Tanaka S, et al. Diagnostic yield of capsule endoscopy vs. double-balloon endoscopy for patients who have undergone total enteroscopy with obscure gastrointestinal bleeding. Hepatogastroenterology 2012;59:955-959.

50. Cúrdia Gonçalves T, Dias de Castro F, Moreira MJ, Rosa B, Cotter J. Smallbowelcapsuleendoscopyinobscuregastrointestinalbleeding: normalcy is not reassuring. Eur J Gastroenterol Hepatol 2014; 26:927-932.

51. Shinozaki S, Yano T, Sakamoto H, et al. Long-term outcomes in patients with overt obscure gastrointestinal bleeding after negative double-balloon endoscopy. Dig Dis Sci 2015;60:3691-3696.

52. Magalhães-Costa P, Bispo M, Santos S, Couto G, Matos L, Chagas C. Re-bleeding events in patients with obscure gastrointestinal bleeding after negative capsule endoscopy. World J Gastrointest Endosc 2015;7:403-410. 
53. Jones BH, Fleischer DE, Sharma VK, et al. Yield of repeat wireless video capsule endoscopy in patients with obscure gastrointestinal bleeding. Am J Gastroenterol 2005;100:1058-1064.

54. Byeon JS, Mann NK, Jamil LH, Lo SK. Is a repeat double balloon endoscopy in the same direction useful in patients with recurrent obscure gastrointestinal bleeding? J Clin Gastroenterol 2013; 47:496-500.

55. Wu LM, Xu JR, Yin Y, Qu XH. Usefulness of CT angiography in diagnosing acute gastrointestinal bleeding: a meta-analysis. World J Gastroenterol 2010;16:3957-3963.

56. Tseng CM, Lin IC, Chang CY, et al. Role of computed tomography angiography on the management of overt obscure gastrointestinal bleeding. PLoS One 2017;12:e172754.

57. Brunnler T, Klebl F, Mundorff S, et al. Significance of scintigraphy for the localisation of obscure gastrointestinal bleedings. World $J$ Gastroenterol 2008;14:5015-5019.

58. Ohri SK, Desa LA, Lee H, et al. Value of scintigraphic localization of obscure gastrointestinal bleeding. J R Coll Surg Edinb 1992; 37:328-332.

59. Howarth DM, Tang K, Lees W. The clinical utility of nuclear medicine imaging for the detection of occult gastrointestinal haemorrhage. Nucl Med Commun 2002;23:591-594.

60. Dusold R, Burke K, Carpentier W, Dyck WP. The accuracy of technetium-99m-labeled red cell scintigraphy in localizing gastrointestinal bleeding. Am J Gastroenterol 1994;89:345-348.

61. Dolezal J, Vizda J, Kopacova M. Single-photon emission computed tomography enhanced Tc-99m-pertechnetate disodium-labelled red blood cell scintigraphy in the localization of small intestine bleeding: a single-centre twelve-year study. Digestion 2011; 84:207-211.

62. Oliveras A, Aubia J, Cao H, et al. 99mTc-labelled red blood cell scintigraphy for localization of gastrointestinal bleeding in chronic renal failure. Nephron 1998;80:76-78.

63. Wang CS, Tzen KY, Huang MJ, Wang JY, Chen MF. Localization of obscure gastrointestinal bleeding by technetium $99 \mathrm{~m}$-labeled red blood cell scintigraphy. J Formos Med Assoc 1992;91:63-68.

64. Howarth DM. The role of nuclear medicine in the detection of acute gastrointestinal bleeding. Semin Nucl Med 2006;36:133-146.

65. Gerson LB. Is there a role for angiography in patients with obscure overt bleeding? Am J Gastroenterol 2012;107:1377-1379.

66. Abbas SM, Bissett IP, Holden A, Woodfield JC, Parry BR, Duncan D. Clinical variables associated with positive angiographic localization of lower gastrointestinal bleeding. ANZ J Surg 2005;75:953-957.

67. Whitaker SC, Gregson RH. The role of angiography in the investigation of acute or chronic gastrointestinal haemorrhage. Clin Radiol 1993;47:382-388.

68. Strate LL, Syngal S. Predictors of utilization of early colonoscopy vs. radiography for severe lower intestinal bleeding. Gastrointest Endosc 2005;61:46-52.

69. Leung WK, Ho SS, Suen BY, et al. Capsule endoscopy or angiography in patients with acute overt obscure gastrointestinal bleeding: a prospective randomized study with long-term followup. Am J Gastroenterol 2012;107:1370-1376.

70. Charbonnet P, Toman J, Bühler L, et al. Treatment of gastrointestinal hemorrhage. Abdom Imaging 2005;30:719-726.

71. Rollins ES, Picus D, Hicks ME, Darcy MD, Bower BL, Kleinhoffer MA. Angiography is useful in detecting the source of chronic gastrointestinal bleeding of obscure origin. AJR Am J Roentgenol 1991;156:385-388.

72. Alkhorayef M, Babikir E, Alrushoud A, Al-Mohammed H, Sulieman A. Patient radiation biological risk in computed tomography angiography procedure. Saudi J Biol Sci 2017;24:235-240.

73. Gölder SK, Schreyer AG, Endlicher E, et al. Comparison of capsule endoscopy and magnetic resonance (MR) enteroclysis in suspected small bowel disease. Int J Colorectal Dis 2006;21:97-104.

74. Wiarda BM, Heine DG, Mensink P, et al. Comparison of magnetic resonance enteroclysis and capsule endoscopy with balloonassisted enteroscopy in patients with obscure gastrointestinal bleeding. Endoscopy 2012;44:668-673.

75. Rajesh A, Sandrasegaran K, Jennings SG, et al. Comparison of capsule endoscopy with enteroclysis in the investigation of small bowel disease. Abdom Imaging 2009;34:459-466.

76. Khalife S, Soyer P, Alatawi A, et al. Obscure gastrointestinal bleeding: preliminary comparison of 64-section CT enteroclysis with video capsule endoscopy. Eur Radiol 2011;21:79-86.

77. Wang Z, Chen JQ, Liu JL, Qin XG, Huang Y. CT enterography in obscure gastrointestinal bleeding: a systematic review and metaanalysis. J Med Imaging Radiat Oncol 2013;57:263-273.

78. Romagnuolo J, Brock AS, Ranney N. Is endoscopic therapy effective for angioectasia in obscure gastrointestinal bleeding?: a systematic review of the literature. J Clin Gastroenterol 2015;49:823-830.

79. Gerson LB, Jackson C. Time to consider medical therapy for smallbowel angioectasias. Am J Gastroenterol 2012;107:1442-1443.

80. Jackson CS, Gerson LB. Management of gastrointestinal angiodysplastic lesions (GIADs): a systematic review and metaanalysis. Am J Gastroenterol 2014;109:474-483; quiz 484.

81. Fan GW, Chen TH, Lin WP, et al. Angiodysplasia and bleeding in the small intestine treated by balloon-assisted enteroscopy. J Dig Dis 2013;14:113-116.

82. Samaha E, Rahmi G, Landi B, et al. Long-term outcome of patients treated with double balloon enteroscopy for small bowel vascular lesions. Am J Gastroenterol 2012;107:240-246.

83. Gerson LB, Batenic MA, Newsom SL, Ross A, Semrad CE. Longterm outcomes after double-balloon enteroscopy for obscure gastrointestinal bleeding. Clin Gastroenterol Hepatol 2009; 7:664-669.

84. Schmit A, Gay F, Adler M, Cremer M, Van Gossum A. Diagnostic efficacy of push-enteroscopy and long-term follow-up of patients with small bowel angiodysplasias. Dig Dis Sci 1996;41:2348-2352.

85. Hutcheon DF, Kabelin J, Bulkley GB, Smith GW. Effect of therapy on bleeding rates in gastrointestinal angiodysplasia. Am Surg 1987;53:6-9.

86. Askin MP, Lewis BS. Push enteroscopic cauterization: longterm follow-up of 83 patients with bleeding small intestinal angiodysplasia. Gastrointest Endosc 1996;43:580-583.

87. Olmos JA, Marcolongo M, Pogorelsky V, Herrera L, Tobal F, Dávolos JR. Long-term outcome of argon plasma ablation therapy for bleeding in 100 consecutive patients with colonic angiodysplasia. Dis Colon Rectum 2006;49:1507-1516.

88. Williamson JB, Judah JR, Gaidos JK, et al. Prospective evaluation of the long-term outcomes after deep small-bowel spiral enteroscopy in patients with obscure GI bleeding. Gastrointest Endosc 2012; 76:771-778.

89. Fudin R, Jaichenko J, Shostak A, Bennett M, Gotloib L. Correction of uremic iron deficiency anemia in hemodialyzed patients: a prospective study. Nephron 1998;79:299-305.

90. Macdougall IC, Tucker B, Thompson J, Tomson CR, Baker LR, Raine AE. A randomized controlled study of iron supplementation in patients treated with erythropoietin. Kidney Int 1996;50:1694-1699.

91. Iannone A, Principi M, Barone M, Losurdo G, Ierardi E, Di Leo A. Gastrointestinal bleeding from vascular malformations: Is octreotide effective to rescue difficult-to-treat patients? Clin Res Hepatol Gastroenterol 2016;40:373-377.

92. Szilagyi A, Ghali MP. Pharmacological therapy of vascular malformationsofthegastrointestinaltract.CanJGastroenterol2006; 20:171-178.

93. Brown C, Subramanian V, Wilcox CM, Peter S. Somatostatin analogues in the treatment of recurrent bleeding from 
gastrointestinalvascularmalformations:anoverviewandsystematic review of prospective observational studies. Dig Dis Sci 2010; 55:2129-2134.

94. Bon C, Aparicio T, Vincent M, et al. Long-acting somatostatin analogues decrease blood transfusion requirements in patients with refractory gastrointestinal bleeding associated with angiodysplasia. Aliment Pharmacol Ther 2012;36:587-593.

95. Scaglione G, Pietrini L, Russo F, Franco MR, Sorrentini I. Longacting octreotide as rescue therapy in chronic bleeding from gastrointestinal angiodysplasia. Aliment Pharmacol Ther 2007; 26:935-942.

96. Chetcuti Zammit S, Sidhu R, Sanders D. Refractory anaemia secondary to small bowel angioectasias - comparison between endotherapy alone versus combination with somatostatin analogues. J Gastrointestin Liver Dis 2017;26:369-374.

97. Rivera M, Lucero J, Guerrero A, et al. [Octreotide in the treatment of angiodysplasia in patients with advanced chronic renal failure]. Nefrologia 2005;25:332-335.

98. Tan HH, GeZZ, Gao YJ, etal. The role ofHIF- 1, angiopoietin-2, Dll4 and Notch1 inbleedinggastrointestinalvascularmalformationsand thalidomide-associated actions: a pilot in vivo study. J Dig Dis 2011; 12:349-356.

99. Bauditz J, Schachschal G, Wedel S, Lochs H. Thalidomide for treatment of severe intestinal bleeding. Gut 2004;53:609-612.

100. Ge ZZ, Chen HM, Gao YJ, et al. Efficacy of thalidomide for refractory gastrointestinal bleeding from vascular malformation. Gastroenterology 2011;141:1629-1637.e1-e4.

101. Garrido A, Sayago M, López J, León R, Bellido F, Márquez JL. Thalidomide in refractory bleeding due to gastrointestinal angiodysplasias. Rev Esp Enferm Dig 2012;104:69-71.

102. Mimidis K, Kaliontzidou M, Tzimas T, Papadopoulos V. Thalidomide for treatment of bleeding angiodysplasias during hemodialysis. Ren Fail 2008;30:1040-1041.

103. Watson AJ, Whelton A. Therapeutic manipulations in uremic bleeding. J Clin Pharmacol 1985;25:315-317.

104. Couch P, Stumpf JL. Management of uremic bleeding. Clin Pharm 1990;9:673-681.

105. Malyszko J, Pietraszek M, Buczko W, Mysliwiec M. Study on mechanisms of a haemostatic effect of 1 deamino-8-D-arginine vasopressin (desmopressin) in uraemic patients. Folia Haematol Int Mag Klin Morphol Blutforsch 1990;117:319-324.

106. Soslau G, Schwartz AB, Putatunda B, et al. Desmopressin-induced improvement in bleeding times in chronic renal failure patients correlates with platelet serotonin uptake and ATP release. Am J Med Sci 1990;300:372-379.

107. Weigert AL, Schafer AI. Uremic bleeding: pathogenesis and therapy. Am J Med Sci 1998;316:94-104.

108. van Cutsem E, Rutgeerts P, Vantrappen G. Treatment of bleeding gastrointestinal vascular malformations with oestrogenprogesterone. Lancet 1990;335:953-955.

109. Hodgson H. Hormonal therapy for gastrointestinal angiodysplasia. Lancet 2002;359:1630-1631.
110. Junquera F, Feu F, Papo M, et al. A multicenter, randomized, clinical trial of hormonal therapy in the prevention of rebleeding from gastrointestinal angiodysplasia. Gastroenterology 2001; 121:1073-1079.

111. Lewis BS, Salomon P, Rivera-MacMurray S, Kornbluth AA, Wenger J, Waye JD. Does hormonal therapy have any benefit for bleeding angiodysplasia? J Clin Gastroenterol 1992;15:99-103.

112. Livio M, Mannucci PM, Viganò G, et al. Conjugated estrogens for the management of bleeding associated with renal failure. $N$ Engl J Med 1986;315:731-735.

113. Liu YK, Kosfeld RE, Marcum SG. Treatment of uraemic bleeding with conjugated oestrogen. Lancet 1984;2:887-890.

114. Shemin D, Elnour M, Amarantes B, Abuelo JG, Chazan JA. Oral estrogens decrease bleeding time and improve clinical bleeding in patients with renal failure. Am J Med 1990;89:436-440.

115. Manzanera MJ, Gutiérrez E, Domínguez-Gil B, García JA, González E, Praga M. [Digestive haemorrhage due to angiodysplasia in dialysis patients. Treatment with conjugated estrogens]. Nefrologia 2005;25:412-415.

116. Bronner MH, Pate MB, Cunningham JT, Marsh WH. Estrogenprogesterone therapy for bleeding gastrointestinal telangiectasias in chronic renal failure. An uncontrolled trial. Ann Intern Med 1986;105:371-374.

117. Richardson JD, Lordon RE. Gastrointestinal bleeding caused by angiodysplasia: a difficult problem in patients with chronic renal failure receiving hemodialysis therapy. Am Surg 1993;59:636-638.

118. Granieri R, Mazzulla JP, Yarborough GW. Estrogen-progesterone therapy for recurrent gastrointestinal bleeding secondary to gastrointestinal angiodysplasia. Am J Gastroenterol 1988; 83:556-558.

119. Chan DK, Soong J, Koh F, Tan KK, Lieske B. Predictors for outcomes after super-selective mesenteric embolization for lower gastrointestinal tract bleeding. ANZ J Surg 2016;86:459-463.

120. Weldon DT, Burke SJ, Sun S, Mimura H, Golzarian J. Interventional management of lower gastrointestinal bleeding. Eur Radiol 2008;18:857-867.

121. Tan KK, Wong D, Sim R. Superselective embolization for lower gastrointestinal hemorrhage: an institutional review over 7 years. World J Surg 2008;32:2707-2715.

122. Funaki B. Superselective embolization of lower gastrointestinal hemorrhage: a new paradigm. Abdom Imaging 2004;29:434-438.

123. Hongsakul K, Pakdeejit S, Tanutit P. Outcome and predictive factors of successful transarterial embolization for the treatment of acute gastrointestinal hemorrhage. Acta Radiol 2014; 55:186-194.

124. Hartmann D, Schmidt H, Bolz G, et al. A prospective two-center study comparing wireless capsule endoscopy with intraoperative enteroscopy in patients with obscure GI bleeding. Gastrointest Endosc 2005;61:826-832.

125. Bonnet S, Douard R, Malamut G, Cellier C, Wind P. Intraoperative enteroscopy in the management of obscure gastrointestinal bleeding. Dig Liver Dis 2013;45:277-284. 